\title{
Lenguas, traductores
}

\section{y naciones que se}

\section{encuentran, en}

\section{la narrativa de la}

Novela ejemplar

mediterránea: "El

amante liberal"

Nieves Rodríguez
Nieves Rodríguez Valle es doctora

en Letras por la Universidad

Nacional Autónoma de México con

la tesis "Poética de los refranes

del Quijote". Recibió la Medalla

Alfonso Caso por sus estudios de

Maestría en 2005. Sus líneas de

investigación versan sobre Cervantes,

la prosa del Siglo de Oro, así como

la literatura oral tradicional, en

especial la paremiología y el estudio

sobre el coyote. Ha impartido

cursos en la Licenciatura en Letras

Hispánicas y en el posgrado de la

UNAM; así como en la Universidad

Panamericana. Es profesora-

investigadora del Centro de Estudios Lingüísticos y Literarios de El Colegio

de México y miembro del Sistema

Nacional de Investigadores. 
CARACOL 6 / DOSSIÊ

Palabras clave:

El amante liberal, lenguas, traducción, otredad.

KEYWORDS

El amante liberal, languages, translation, otherness.
RESUMEN

En este artículo se analizan las estrategias narrativas que utiliza Cervantes para presentar el mundo Mediterráneo de "El amante liberal" a través de recursos como la descripción, la comparación con lo conocido, que busca establecer equivalencias unas veces, igualdad de términos, otras, la adopción de palabras y la utilización de la figura del traductor, la cual da cuenta de la necesidad narrativa de expresar las barreras lingüísticas, de la diversidad de lenguas: turco, árabe, griego, italiano y lengua franca, que dan testimonio de la multiplicidad de etnias y religiones que coexisten en este mundo cosmopolita. La liberalidad del narrador y los personajes en intentar transmitir la diversidad del mundo.

\section{ABSTRACT}

In this article, we analyze the narrative strategies that Cervantes uses to present the Mediterranean world of "El amante liberal". This is done through methods like description and comparison with the recognizable, which establishes equivalences, identity of terms, and apropiation of words and utilization of the translator's figures, who gives account of the narrative necessity of expressing the linguistic barriers of the language diversity: turquish, arabish, Greek, Italian and the lengua Franca. It gives testimony of the multiplicity of ethnicities and religions that coexist in this cosmopolitan world. The liberalidad of the narrator and the characters is an intent to transmit the world's diversity. 
LENGUAS, TRADUCTORES Y NACIONES QUE SE ENCUENTRAN, EN LA NARRATIVA

de la Novela ejemplar mediterránea: “El amante liberal"

Nieves Rodrícuez

"El amante liberal" es la segunda novela según el orden en que acomoda Cervantes sus Novelas ejemplares, y es una de las tres cuya acción sucede fuera de España; en ella convergen temas ya explorados en el conjunto de su producción: amor, belleza, cautiverio, libertad, aventura, contacto entre el mundo cristiano y el islámico; y por explorar, como los avatares de la novela bizantina: viajes, naufragios, desencuentros, sucesos extraordinarios, que aguardan amplio desarrollo en el Persiles. La gran novedad temática de esta novela es la aventura hacia el despertar interior; el protagonista en el cautiverio ha perdido la esperanza de la fortuna amorosa, fortuna que ya no poseía cuando era libre y que le favorecerá cuando, recobrada la libertad, se libere también de las cadenas interiores y descubra que la liberalidad (generosidad, desprendimiento) en el amor es el dar sin esperar recompensa y el reconocer al objeto del amor como sujeto libre. La novela está enmarcada entre dos discursos del protagonista, en el primero, Ricardo, cautivo, se lamenta ante las ruinas de Nicosia, la cual, como él, es desdichada, en el último, Ricardo, libre, en su patria Trápana (Trapani, Sicilia) alcanza la dicha, resurgido de sus ruinas. El lamento inicial permite a Cervantes, además del tema central, llevarnos por un viaje Mediterráneo y abordar el encuentro entre naciones y sus desencuentros, pues la acción sucede en la cuenca del conflictivo Mediterráneo en lucha entre cristianos y musulmanes; el espacio narrativo abarca prácticamente todo este mar en el que convergen distintos personajes, razas, religiones, costumbres y lenguas.

El Mediterráneo ha sido constante fuente de inspiración; desde la narrativa homérica, el mar ha representado el ambiente funesto por el que transcurren viajes, trabajos y aventuras; en la novela bizantina, el mar siempre está presente, es "un entorno misteriosos, peligroso e impredecible, que puede conducir a los enamoraos hacia un final regreso al hogar o desampararlos 
con una violenta tormenta que haga naufragar cualquier embarcación" (González-Barrera, 1997, 87). El Mediterráneo se vuelve un motivo literario en el que aparecen piratas, tormentas, rivales amorosos, separaciones, con las consiguientes capturas en donde los personajes son llevados a tierras lejanas, salvajes y exóticas. En los modelos clásicos, "la esclavitud se convierte en una de las pruebas más difíciles para los enamorados, pues, además de la pérdida de la libertad y el riesgo de apostasía, está la presencia de antagonistas en forma de ardorosos pretendientes, que ofrecen a los enamorados la libertad, títulos y riquezas a cambio de su amor" (González-Barrera, I997, 87-88). Todo esto está presente en la estructura de "El amante liberal"; pero, lo que en las novelas de Heliodoro y Aquiles Tacio representa un mundo lejano, exótico e incluso irreal, en la España de Cervantes, este espacio y estas circunstancias son reales. Mientras que la novela griega se sitúa en un mundo abstractamente extranjero, Cervantes hace una "yuxtaposición intencionada de lo que es extranjero a lo que es familiar, habitual y conocido" (Cardaillac, I980, 2I).

En el siglo xv, la conquista de Constantinopla por los otomanos y la del reino de Granada por los Reyes Católicos cambian el mapa político del Mediterráneo. El conflicto entre cristianos y musulmanes, a pesar de ser una guerra no declarada, estuvo presente durante doscientos años; de hecho, entre la Corona española y el Imperio otomano sólo se produjo una batalla de consideración; sin embargo, el fruto de esta guerra implícita son el cautiverio y los cautivos, pues representaron una forma de vida y de actividad monetaria y laboral con unas características propias (De Bunes, I989, I40-I4I). El mar y sus costas constituyen un espacio de tensiones políticas y de amenazas representadas tanto por las armadas como por los piratas y corsarios que proliferan asaltando costas y navíos que transportan mercancías. 
LENGUAS, TRADUCTORES Y NACIONES QUE SE ENCUENTRAN, EN LA NARRATIVA

de la Novela ejemplar mediterránea: “El amante liberal"

Nieves Rodrí́cuez

Con la inclusión de la realidad histórico-geográfica y de las incursiones de piratas a las poblaciones costeras mediterráneas en búsqueda de cautivos, los espacios maravillosos de la novela bizantina, se dejan de lado para ubicarse en un mundo a la vez familiar y lejano para el público de la época. Esta realidad origina el cautiverio de Ricardo y Leonisa. Ricardo, enamorado y no correspondido, según su propio relato, explica su cautiverio sucedido "hoy hace un año, tres días y cinco horas" (Cervantes, 200I, I67): Sabiendo que Leonisa y su pretendiente Cornelio junto con sus familias se iban a solazar "al jardín de Ascanio, que está cercano a la marina, en el camino de las Salinas" (I67), lleno de furia, rabia e infierno de celos, se aparece en el jardín, expresa su dolor y mientras reta a Cornelio:

de improviso dieron en el jardín mucha cantidad de turcos de dos galeotas de corsarios de Biserta, que en una cala, que allí cerca estaba, habían desembarcado sin ser sentidos de las centinelas de las torres de la marina, ni descubiertos de los corredores o atajadores de la costa. [...] Este asalto hicieron los turcos con su acostumbrada diligencia (I70).

Del jardín "cautivan" a Leonisa, que se había desmayado, y a tres personas más; Ricardo es también atrapado y resulta herido al pelear y matar a cuatro turcos; con esto inicia la aventura y Ricardo explica porqué está en el presente del relato cautivo en Nicosia.

Aunque el cautiverio y la piratería son muy antiguos, "la preocupación por los cautivos se imbrica directamente a Miguel de Cervantes y la capital del estado berberisco. De hecho, el autor del Quijote y Argel han pasado a ser considerados como la representación y el símbolo del cautiverio en la Edad Moderna" (De Bunes, I989, I39). El tema del cautiverio no sólo marca la vida de Cervantes sino que, y tal vez por ello, atraviesa su obra en los distintos momentos y géneros de su producción literaria, desde algunos pasajes de La 
Galatea, hasta los 'falsos' cautivos del Persiles. Es Cervantes a quien corresponde el mérito de haber convertido el cautiverio y su escena en un mundo complejo de creación artística; ya no es la idealización de la literatura morisca, sino la experiencia propia en este mundo ajeno. En su cautiverio, Cervantes entra en contacto con "ese Argel tan rico en diversidad humana y religiosa -turcos, moriscos, bereberes, griegos, italianos, españoles, judíos, eslavos, todos con su idioma y ropa distintivos- en el que el estado musulmán no vedaba la práctica del judaísmo o del cristianismo, cosa que desde 1492 no se había visto en España, convertida, en la superficie por lo menos, en un país unánimemente católico" (King, I992, 279).

Ricardo narra su desventura a Mahamut, quien representa otra figura que es consecuencia del conflicto entre cristianos e islámicos, la del renegado, aquel que, para mejorar su situación renegaba de su fe y se convertía a la del captor. Los cristianos que se convertían al islam eran llamados 'renegados'; peso enorme para la concepción de la fidelidad cristiana y de la prueba de la "verdad" de su fe; sin embargo, los renegados fácilmente podían ser recibidos de nuevo por la Iglesia. Mahamut, natural de Palermo, Siciliano como Ricardo, afirma que desea "no morir en este estado que parece que profeso" (200I, I63), "pues cuando más no pueda, tengo de confesar y publicar a voces la fe de Jesucristo, de quien me apartó mi poca edad y menos entendimiento" (I64); Mahamut será no sólo quien escuche las penas amorosas de Ricardo sino quien ayude a remediar el cautiverio: "quizá para que yo te sirva ha traído la fortuna este rodeo de haberme hecho vestir de este hábito, que aborrezco" (i63). Cervantes, como Ricardo con su amigo Mahamut, había tenido gran contacto con renegados.

En "El amante liberal", Cervantes nos lleva a un conocimiento más profundo de este Mediterráneo; el cautiverio en esta novela es el intermedio e intermediario en la historia amorosa de un Ricardo liberal que recibirá la 
LENGUAS, TRADUCTORES Y NACIONES QUE SE ENCUENTRAN, EN LA NARRATIVA de la Novela ejemplar mediterránea: “El amante liberal"

Nieves Rodrí́cuez

correspondencia a su amor una vez que suceda su retorno; mientras tanto, junto con el renegado, nos muestra este mundo de otros, y, a través de los personajes y las acciones, conocemos las costumbres, los ritos, las lenguas y las necesidades de comunicación que forman parte del universo creativo de Cervantes.

Tras el lamento de Ricardo con que inicia la novela, él y el renegado nos adentran en el mundo islámico, a través de recursos que se utilizan toda vez que se intenta nombrar una realidad desconocida. Cuando los españoles desembarcaron en el Nuevo Mundo, por ejemplo, se encontraron un ambiente cultural y geográfico desconocido al cual debían nombrar; para ello, como afirma Alvar, se valieron de la comparación con lo conocido, de la descripción y, finalmente, en algunos casos, de la adopción de la palabra indígena (I99I, 40).

Siguiendo este esquema, en la narrativa cervantina de esta novela encontramos la descripción minuciosa de vestidos, de costumbres tanto religiosas como de cambio de poderes, impartición de justicia y reparto de botín. Los personajes que integran el relato son sicilianos, corsarios turcos, corsarios griegos, corsarios cristianos, cautivos cristianos (remeros), renegados italianos y griegos, un rico mercader judío, un cadí y dos bajás. Descripción que se encuentra también con la necesidad narrativa de expresar las barreras lingüísticas de la diversidad de lenguas: turco, árabe, griego, italiano y "lengua franca", que dan testimonio de "la multiplicidad de las etnias y de las religiones, así como el cosmopolitismo de este mundo" (Cardaillac, I980, 23). El Narrador nos cuenta cómo el mismo cadí es consciente de esta diversidad, pues cuando el nuevo bajá (amo de Ricardo) va a entrar en posesión de la plaza de Nicosia, siguiendo la costumbre: "salió el cadí a la puerta de la tienda, y dijo a voces en lengua turquesca, arábiga y griega, que todos los que quisiesen entrar a pedir justicia, u otra cosa contra Alí Bajá, podrían entrar libremente" (200I, I8I); lo 
hacen así y el Narrador comenta: "Y entre aquellos bárbaros, si lo son en esto, el cadí es el juez competente de todas las causas, que las abrevia en la uña y las sentencia en un soplo, sin que haya apelación de su sentencia para otro tribunal" (200I, I8I-I82).

No sólo encontramos descripciones, sino que "El amante liberal" está lleno de aclaraciones léxicas que cumplen la función propia de un narrador que quiere mostrar y hacer entender una cultura a otra. Continuando con el esquema de Alvar, encontramos en "El amante liberal" voces árabes y turcas explicadas por comparación con lo conocido para su lector, como lo hace el renegado al establecer equivalencias entre las jerarquías eclesiásticas, explicando y caracterizando la figura del cadí, central en la novela: "Ya sabes, Ricardo, que es mi amo el cadí de esta ciudad, que es lo mismo, que ser su obispo" (200I, I63). Para el Diccionario de la Real Academia vigente, 'cadi' “(del francés cadi, y este del árabe clásico qāọī), entre turcos y moros, es el juez que entiende en las causas civiles" (DRAE), pero, en la novela es claro que se trata de una figura religiosa importante, efectivamente equivalente a la de obispo, como vuelve a comentar el Narrador: "A las palabras del cadí obedecieron luego; y aun si otra cosa más dificultosa les mandara, hicieran lo mismo, tanto es el respeto que tienen a sus canas los de aquella dañada secta" (200I, I84); "Con tales afectos decía su pasión el religioso moro" (200I, I93); y pregunta el mismo cadí a su atacante: “¿Cómo, maldito, has osado poner las manos y las armas en tu cadí, y en un ministro de Mahoma?" (200I, 207).

Este recurso que comienza en voz del renegado también lo utilizan Ricardo y el Narrador. Ricardo encuentra similitud entre los cargos civiles o políticos cuando pregunta por qué "Hazán Bajá, mi amo, ha hecho plantar en Nicosia, adonde viene proveído por virrey o por bajá, como los turcos llaman a los virreyes" (200I, I64). 
LENGUAS, TRADUCTORES Y NACIONES QUE SE ENCUENTRAN, EN LA NARRATIVA

de la Novela ejemplar mediterránea: “El amante liberal"

Nieves Rodrí́cuez

Mahamut en su respuesta nos introduce a las costumbres turcas también por comparación con la organización política española:

Hecha, pues, la residencia, se la dan al que deja el cargo en un pergamino cerrado y sellado, y con ella se presenta a la Puerta del Gran Señor, que es como decir en la Corte ante un Gran Consejo del Turco; la cual vista por el visir-bajá, y por los otros cuatro bajás menores, como si dijésemos ante el presidente del Real Consejo y oidores, o lo premian o lo castigan, según la relación de la residencia (200I, I64-I65).

La comparación incluso puede derivar en la igualdad de términos, por ejemplo, nos dice el Narrador: "En esto entró un chauz, que es como alguacil" (200I, I82); que se encuentra en el Diccionario como equivalente: "Quizá del portugués chaus, y este del turco çavuş. Entre los árabes, portero de estrados, alguacil o ministro del juez” (DRAE). También se incluyen equivalencias monetarias: "El codicioso judío respondió que cuatro mil doblas, que vienen a ser dos mil escudos" (200I, I83) y uso de frases: "[...] los turcos saltaron en tierra a hacer leña y carne, como ellos dicen; [...]" (200I, I73).

En "El amante liberal" también existe la traducción directa, es decir el traslado de un concepto a su correspondiente en otra lengua: ya sea de jerarquías militares, ya de nobleza, ya de construcciones navales, ya de prendas de vestuario. Ricardo le traduce a Mahamut quien seguramente lo sabe para que el lector comprenda:

Hicieron reseña por ver qué gente les faltaba, y viendo que los muertos eran cuatro soldados de aquellos que ellos llaman leventes, y de los mejores y más estimados que traían quisieron tomar en mí la venganza, y así mandó el arráez de la capitana bajar la entena para ahorcarme (200I, I7I). 
CARACOL 6 / DOSSIÊ

El Narrador realiza dos traducciones léxicas mientras trascurre el relato:

Venía cubierto el rostro con tafetán carmesí; por las gargantas de los pies que se descubrían, parecían dos carcajes, que así se llaman las manillas en arábigo, al parecer de puro oro (200I, I82).

Díjole cómo el cadí había traído a su casa un cautivo cristiano de tan gentil donaire y parecer, que a sus ojos no había visto más lindo hombre en toda su vida, y que decían que era chilibí, que quiere decir caballero (200I, I93).

Leonisa, por su parte, cuando le narra a Ricardo las peripecias de su llegada a Nicosia, le aclara:

A los ocho días llegó a aquella costa un bajel de moros que ellos llaman caramuzales; viéronle los turcos, y salieron de donde estaban, haciendo señas al bajel, que estaba cerca de tierra, tanto que conoció ser turcos los que llamaban (200I, I98).

Los personajes se valen de algunas fórmulas que hacen consciente y presente el intento de explicar el mundo ajeno, así tenemos las empleadas para introducir la comparación: 'que es lo mismo', 'como los turcos llaman', 'es como decir' 'que es como'; las que se utilizan para presentar la traducción: 'que ellos llaman', 'que quiere decir', 'que así se llaman en arábigo'; para las equivalencias: 'que vienen a ser' y para el uso de frases: 'como ellos dicen'. De este modo, ellos, y el nosotros implícito, pueden establecer un puente entre las lenguas (dentro y fuera del relato) que acrecienta la naturaleza de estar cautivos en un mundo extraño que los personajes desean (porque necesitan) conocer y transmitir. Juego narrativo que se acrecienta, pues el relato tendría que estar en italiano que es la lengua de los protagonistas, lo que implícitamente ha requerido de un traductor para el lector hispano. 
LENGUAS, TRADUCTORES Y NACIONES QUE SE ENCUENTRAN, EN LA NARRATIVA

de la Novela ejemplar mediterránea: “El amante liberal"

Nieves Rodrí́cuez

La adopción de las palabras del otro idioma con que se entra en contacto se debe, por lo general, a que nombran objetos propios de la cultura, como el manto de los moros: "El vestido era una almalafa de raso verde, toda bordada y llena de trencillas de oro" (200I, I85); o los soldados de infantería de la guardia del Gran Turco: "Venía acompañado Alí Bajá, que así se llamaba el que dejaba el gobierno, de todos los jenízaros que de ordinario están de presidio en Nicosia después que los turcos la ganaron, que serían hasta quinientos" (200I, I80).

Cervantes va más allá cuando además intenta reproducir el problema de la incomunicación por la barrera lingüística y para ello se vale de la figura de un traductor. Desde el momento en que son hechos cautivos Ricardo y Leonisa, surge la necesidad de entender pues los contactos entre grupos o individuos cuyas respectivas lenguas se desconocen implican más complejidad: la posibilidad de ocultamiento de intenciones y el desconocimiento de la realidad ajena (cultura, códigos, costumbres) introducen un elemento de falta de control en la situación y, por lo tanto, de riesgo (Payas, 20Io, 88). En la narración de los sucesos que siguen a la captura por los corsarios, Ricardo describe cómo Leonisa pone toda su atención para intentar saber qué dicen los turcos cuando ve que el arráez (capitán del navío) manda bajar la entera para ahorcar a Ricardo; afortunadamente para ella, en el barco viene un cautivo que conoce ambas lenguas y funciona como traductor:

Todo esto estaba mirando Leonisa, que ya había vuelto en sí, y viéndose en poder de los corsarios, derramaba abundancia de hermosas lágrimas, y torciendo sus manos delicadas, sin hablar palabra, estaba atenta a ver si entendía lo que los turcos decían. Más uno de los cristianos del remo le dijo en italiano cómo el arráez mandaba ahorcar a aquel cristiano, señalándome a mí, porque había muerto en su defensa cuatro de los mejores soldados de las galeotas. Lo cual oído y entendido por Leonisa, a la vez 
primera que se mostró para mí piadosa, dijo al cautivo que dijese a los turcos que no me ahorcasen, porque perderían un gran rescate [...]. Oyendo, pues, los turcos lo que el cautivo les decía, le creyeron, y mudóles el interés la cólera (Cervantes, 200I, I7I).

La rareza del idioma, el no comprender y el no hacernos entender a los que hablan diferente hacen patente el exotismo de lo ajeno y la pertenencia a comunidades distintas (Alonso, 2010, 49); para salvar esas barreras, los intérpretes son, por definición, quienes tienen la capacidad de rebasar fronteras lingüísticas y culturales (Alonso, 2010, 56). Para que pueda existir la comunicación, ha de haber intención comunicativa y un código que permita acercar posiciones entre las dos partes. Como afirma Baigorri, el aprendizaje de la lengua del otro se ha de apoyar en una motivación suficiente (2010, 20); cautivos y renegados se ven forzados a conocer el idioma del captor para su auto-preservación.

Por medio de este intermediario y gracias al intercambio que sucede entre Leonisa y el cristiano de remo, y de éste con los corsarios, Ricardo se salva debido a la codicia de los corsarios, quienes intentan volver a tierra para negociar el rescate, sin embargo, vuelven a partir pues divisan barcos cuyas señas indican que pertenecen a la armada cristiana; llegan a Pantanalea, isla entre Sicilia y Túnez y ahí los capitanes de los navíos (Yzuf, renegado griego, y Fetala) se reparten el botín. Durante este reparto es ahora Ricardo el que está interesado en saber cuál es el destino que le depara a Leonisa:

y aunque estuve presente a todo esto, nunca pude entender lo que decían, aunque sabía lo que hacían, ni entendiera por entonces el modo de la partición si Fetala no se llegara a mí y me dijera en italiano: 'Cristiano, ya eres mío; en dos mil escudos de oro te me han dado; si quieres libertad, has de dar cuatro mil; si no, acá morir'. Preguntéle si era también suya la cristiana: díjome que no, sino que Yzuf se quedaba con ella, con 
LENGUAS, TRADUCTORES Y NACIONES QUE SE ENCUENTRAN, EN LA NARRATIVA

de la Novela ejemplar mediterránea: “El amante liberal"

Nieves Rodrí́cuez

intención de volverla mora y casarse con ella. Y así era la verdad, porque me lo dijo uno de los cautivos del remo que entendía bien el turquesco, y se lo había oído tratar a Yzuf y a Fetala (Cervantes, 200I, I73-I74).

Ricardo también necesita de un traductor, en este caso no es un cristiano o un renegado sino un musulmán que conoce el italiano; Ricardo en su narración incluso reproduce la entonación de este capitán que ha aprendido otra lengua. Para que no quede duda en la intención del capitán, Ricardo añade en su relato la confirmación que recibe por parte de uno de los cautivos de remo que "entendía bien el turquesco".

Mahamut, por su parte, será también el traductor de Leonisa, lo que le permitirá funcionar así mismo como intermediario entre ella y Ricardo: "En el camino que había desde las tiendas a la ciudad, tuvo lugar Mahamut de preguntar a Leonisa en lengua italiana que de qué lugar era. La cual le respondió que de la ciudad de Trápana” (I87).

Finalmente, en la novela se incluye la referencia a la 'lengua franca' ("La que es mezcla de dos o más, y con la cual se entienden los naturales de pueblos distintos", DRAE):

Vete con Dios, que temo no nos haya escuchado Halima, la cual entiende algo de la lengua cristiana, a lo menos de aquella mezcla de lenguas que se usa, con que todos nos entendemos (Cervantes, 200I, 200-20I).

El Mediterráneo de "El amante liberal" es un lugar de desencuentros trágicos y de encuentros felices; un espacio para la aventura, los crímenes, los naufragios, la salvación externa e interna; un mar cuyas olas son torres de Babel en movimiento que llegan a tocar las orillas. Cervantes nos muestra cómo la ceguera de Ricardo ante lo que significa ser una amante, puede por analogía 
llevarnos a la ceguera ante el mundo de los otros. El encuentro y la liberación se produce si existe una intención comunicativa, si se mira al otro y se intenta comprenderlo; la liberalidad consiste entonces también en intentar transmitir la diversidad del mundo y para ello se necesita ser un viajero.

\section{REFERENCIAS BIBLIOGRÁFICAS}

Alonso Araguás, Icíar. "Figuras mediadoras y espacios fronterizos. Algunos lugares comunes". Los límites de Babel. Ensayos sobre la comunicación entre lenguas y culturas, Madrid: 200I, Iberoamericana / Vervuert, 47-76.

Alvar López, Manuel. El español de las dos orillas. Madrid: I99I, Mapfre.

Baigorri Jalón, Jesús. “Transnacionalidad, lengua y comunicación: hacia unos modelos de diálogo intercultural", Los límites de Babel. Ensayos sobre la comunicación entre lenguas y culturas. Madrid: 2010, Iberoamericana / Vervuert, I33-I53.

Cardaillac, Luis y Denise, Marie-Thérese Carriere, y Rosita Subiraes. "Para una nueva lectura de El amante liberal", Criticón Io, 1980, 13-29.

Cervantes, Miguel de, Novelas ejemplares, Juan Bautista Avalle-Arce (ed.), Tres tomos, Madrid: 200I, Castalia.

De Bunes Ibarra, Miguel Ángel, La imagen de los musulmanes y del Norte de África en la España de los siglos xvi $y$ xvii. Los caracteres de una hostilidad, Madrid: I989, Consejo Superior de Investigaciones Científicas.

García Arenal, Mercedes y Miguel Ángel de Bunes, Los españoles y el norte de África. Siglos xv-xviii, Madrid: 1992, Mapfre.

González-Barrera, Julián. "La novela bizantina española y la comedia La doncella Teodor de Lope de Vega. Primera aproximación hacia un nuevo subgénero dramático", Quaderni Ibero-americani, I, I997, 76-93. 
LENGUAS, TRADUCTORES Y NACIONES QUE SE ENCUENTRAN, EN LA NARRATIVA de la Novela ejemplar mediterránea: “El amante liberal"

Nieves RodríGuez

King, Willard. "Cervantes, el cautiverio y los renegados”, Nueva Revista de Filología Hispánica, XL, núm. I, I992, 279-29I.

Osterc, Lúdovik, La verdad sobre las novelas ejemplares (Obra completa), México,

Facultad de Filosofía y Letras, Universidad Nacional Autónoma de México, I995.

Payas Puigarnau, Gertrudis. “Tras la huella del intérprete en la historia colonial hispanoamericana", Los límites de Babel. Ensayos sobre la comunicación entre lenguas y culturas. Madrid: Iberoamericana / Vervuert, 2010, 77-99.

Stoopen Galán, María. Cervantes transgresor. México, Facultad de Filosofía y Letras, Universidad Nacional Autónoma de México, 2010. 


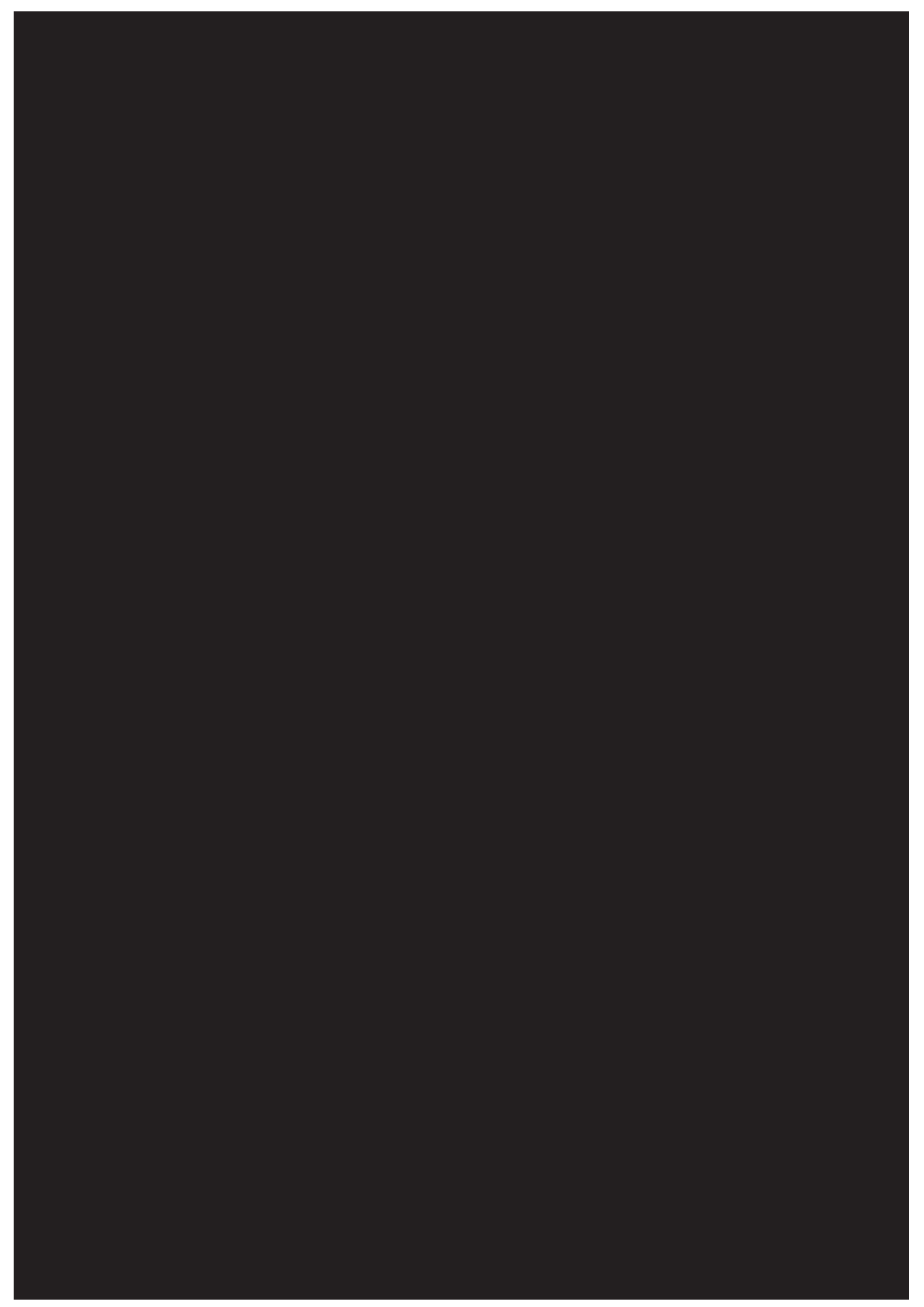

